\title{
Optimal Allocation of Tunnel Safety Provisions Based on a Quantitative Risk Assessment Model
}

\author{
Pan $\mathrm{Li}^{1}$ and Xiaobo $Q \mathbf{u}^{2}$ \\ ${ }^{1}$ School of Urban Rail Transportation, Soochow University, Suzhou, Jiangsu 215131, China \\ ${ }^{2}$ School of Civil and Environmental Engineering, University of Technology Sydney, Sydney, NSW 2007, Australia
}

Correspondence should be addressed to Xiaobo Qu; xiaobo.qu@uts.edu.au

Received 13 September 2016; Accepted 10 November 2016

Academic Editor: Si Zhang

Copyright (C) $2016 \mathrm{P}$. Li and X. Qu. This is an open access article distributed under the Creative Commons Attribution License, which permits unrestricted use, distribution, and reproduction in any medium, provided the original work is properly cited.

\begin{abstract}
This paper addresses the issue of optimally selecting the tunnel safety provisions. Tunnel safety provisions are the assets of urban road tunnels which are installed and implemented to reduce the tunnel risks, which are basically selected by expert judgment in practice. An optimization model is proposed to obtain the optimal solution for the selection of tunnel safety provisions. The objective function is to minimize the life cycle costs of tunnel safety provisions, which is subject to the requirements for tunnel safety provisions and the safety targets. Finally, by taking advantage of the special structure of the optimization model, a Bi-Section Search and Bound Algorithm (BSSBA) is designed to efficiently solve the problem.
\end{abstract}

\section{Introduction}

Urban road tunnels have been more and more important infrastructure which provide underground vehicular passageways for motorists and commuters, especially in populous cities like Singapore and Hong Kong. With the increased travel demand and urbanization as well as the limited land supply, building urban road tunnels has been an alternative to improve the capacity of our transport networks. However, urban road tunnels lead to serious safety challenges due to their semienclosed environment. As a result, various tunnel safety provisions are required to be installed in order to control the loss caused by a certain incident.

The most common provisions include tunnel detection system, tunnel verification system, tunnel ventilation system, and firefighting system. Every system has various types with different functional parameters. For example, there are two types of tunnel ventilation systems-transverse ventilation and longitudinal ventilation. The former is to protect the tunnel users by keeping the smoke stratified in a hot layer underneath the ceiling of the tunnel and extracting it at the ceiling, while the latter is to prevent backlayering $[1,2]$. In practice, the selection of tunnel safety provisions is on the basis of expert judgment by taking the risk assessment results into account. In reality, the tunnel safety provisions are designed at the planning stage. Once the tunnel is open to traffic, these parameters are considered to be unadjustable; it would be difficult, if not impossible, to adjust these parameters to reduce the risks. Therefore, it is of great importance to assess the risks when selecting tunnel safety provisions at the planning stage by assuming possible traffic conditions.

It is now a common practice to apply engineering economics principles in the evaluation of transportation projects, such as highways, bridges, and pavements[3]. Life cycle cost analysis (LCCA) is considered as an effective assessment tool for analyzing the performance of complex systems [4]. It was introduced in the fields of infrastructures in the early 1980s as an appraisal tool for the total cost of ownership over the lifespan of an asset $[5,6]$.

The total costs with respect to tunnel safety provisions include purchase cost, maintenance cost, and operating cost. The purchase cost refers to the price at which one tunnel safety provision is actually purchased and implemented. The maintenance cost is the money used to upkeep the tunnel safety provision. The operating cost includes the electrical cost of the tunnel safety provision and the salaries of operators for the provision. The salvage cost is usually assumed to be zero in the analysis of tunnel safety provisions. The 
different types of tunnel safety provisions with distinct cost compositions and life spans could be evaluated in the LCCA framework.

\section{Notations and Explanations}

Henceforth, the following notations apply:

$V_{p}^{i}$ is the purchase cost of the tunnel ventilation system with type $i$.

$V_{m}^{i}$ is the maintenance cost of the tunnel ventilation system with type $i$.

$V_{o}^{i}$ is the operating cost (the electrical cost and salaries of operators) of the tunnel ventilation system with type $i$.

$D_{p}^{j}$ is the purchase cost of the fire detection system with type $j$.

$D_{m}^{j}$ is the maintenance cost of the fire detection system with type $j$.

$D_{o}^{j}$ is the operating cost (the electrical cost and salaries of operators) of the fire detection system with type $j$.

$F_{p}^{k}$ is the purchase cost of the fire verification system with type $k$.

$F_{m}^{k}$ is the maintenance cost of the fire verification system with type $k$.

$F_{o}^{k}$ is the operating cost (the electrical cost and salaries of operators) of the fire verification system with type $k$.

$V^{i}$ is the annual worth of the tunnel ventilation system with type $i$.

$D^{j}$ is the annual worth of the fire detection system with type $j$.

$F^{k}$ is the annual worth of the fire verification system with type $k$.

$n_{v}^{i}, n_{d}^{j}$, and $n_{f}^{k}$ are the study period for tunnel ventilation system with type $i$, fire detection system with type $j$, and fire verification system with type $k$, respectively.

The purchase costs and maintenance costs of various types of tunnel safety provisions are obtainable from the conceptual design of the tunnel project. The operating costs could be estimated by the experienced tunnel operators. By using LCCA, we can estimate the annual worth for each combination of candidate tunnel safety provisions.

\section{QRA Model Based Optimal Selection of Tunnel Safety Provisions}

3.1. Model Formulation. As mentioned earlier, it would be difficult, if not impossible, to change or upgrade the tunnel safety provisions to reduce the risks as soon as a tunnel is open to traffic. Consequently, on the one hand, the tunnel risks in the life span of the tunnel should be managed to be within the safety targets; on the other hand, the decisions makers (e.g., LTA of Singapore) may want to minimize the total costs. In this research, a QRAM based optimal selection approach is proposed to support decision makers.

Sherali et al. [7] proposed a risk reduction optimization (RRO) model to optimally allocate the available resources on the basis of a QRA model for gasoline rupture situation related to an offshore oil and gas production platform. Their RRO model is to minimize risks (in terms of expected loss), subject to the budget and resources constraints. However, the formulation cannot be applied to the current study. Since the safety targets are compulsory by regulations to be fulfilled in road tunnel risk assessment, we should put the risks as the constraints rather than the object to be minimized.

Let AW denote the annual worth of the total costs of various types of tunnel safety provisions. We further define binary variables $x^{i}, y^{j}$, and $z^{k}$ as follows:

$$
\begin{aligned}
& x^{i} \\
& = \begin{cases}1, & \text { if the tunnel ventilation system with type } i \text { is selected; } \\
0, & \text { otherwise }\end{cases} \\
& y^{j}= \begin{cases}1, & \text { if the fire detection system with type } j \text { is selected; } \\
0, & \text { otherwise, }\end{cases} \\
& z^{k} \\
& = \begin{cases}1, & \text { if the fire verification system with type } k \text { is selected; } \\
0, & \text { otherwise. }\end{cases}
\end{aligned}
$$

Thus, we have the objective function as follows:

$$
\begin{array}{cl}
\min \quad & \mathrm{AW}=\sum_{i=1}^{I} x^{i} V^{i}+\sum_{j=1}^{J} y^{j} D^{j}+\sum_{k=1}^{K} z^{k} F^{k} \\
\text { Subject to: } \quad \sum_{i=1}^{I} x^{i} \geq 1, \\
\\
\sum_{j=1}^{J} y^{j} \geq 1 \\
\\
\sum_{k=1}^{K} z^{k} \geq 1, \\
\operatorname{SR}_{\alpha}(\vec{x}, \vec{y}, \vec{z}) \leq \mathrm{SR}_{\text {criterion }} \\
\operatorname{IR}_{\beta}(\vec{x}, \vec{y}, \vec{z}) \leq \mathrm{IR}_{\text {criterion }}, \\
\operatorname{EV}_{\beta}(\vec{x}, \vec{y}, \vec{z}) \leq \mathrm{EV}_{\text {criterion }} \\
x^{i}, y^{j}, z^{k}=0,1 .
\end{array}
$$

In this formulation, the objective function (2) seeks to minimize the total costs; constraints (3) to (5) imply that tunnel ventilation systems, fire detection systems, and fire 
verification systems are compulsory components; that is, at least one type should be chosen, for urban road tunnels in Singapore according to the Project Safety Review Manual for roads in Singapore; constraint (6) indicates that the $\alpha$ cut based societal risk should not be beyond a predetermined safety target $\left(\mathrm{SR}_{\text {criterion }}\right)$; constraints (7) and (8) represent that the $\beta$ percentile based individual risk and expected value of fatalities should be less than or equal to the corresponding predetermined safety targets ( $\mathrm{IR}_{\text {criterion }}$ and $\left.\mathrm{EV}_{\text {criterion }}\right)$, respectively. (Please refer to [8-11] for risk assessment and risk indices.)

3.2. Algorithm. The optimization model formulated in Section 3.1 is a typical integer nonlinear programming model. Thanks to constraints (3) to (5), there would be only limited number of feasible combinations of tunnel safety provisions. Theoretically, the numbers of solutions satisfying constraint (3), constraint (4), and constraint (5) are $2^{I}-1,2^{J}-1$, and $2^{K}-1$, respectively. If the number of these tunnel safety provisions increased, the computational complexity of the optimization model would be dramatically increased. In practice, the experts from land transport authorities may only provide a few candidate tunnel safety provisions (usually $I \leq$ $3, J \leq 4$, and $K \leq 4$ ). If $I$ is equal to 3 and $J$ and $K$ are both equal to 4 , the number of solutions satisfying constraints (3) to (5) is 1575 . Under such circumstance, it would be very timeconsuming (although it is possible) to enumerate all solutions satisfying constraints (3) to (5) and check whether or not they fulfil the safety targets (constraints (6) to (8)).

Addition of new tunnel safety provisions will at least not increase (most probably reduce) the tunnel risks; that is, any additional investments on tunnel safety provisions will not increase the tunnel risks. For example, assume we have a solution (solution 1), represented by

$$
\begin{aligned}
& \vec{x}=(1,0,0), \quad I=3 \\
& \vec{y}=(0,1,1,0), \quad J=4 \\
& \vec{z}=(0,0,0,1), \quad K=4 .
\end{aligned}
$$

The solution suggests that type 1 of ventilation system, types 2 and 3 of fire detection system, and type 4 of fire verification system are implemented in the road tunnel. Evidently, if the solution satisfies constraints (6) to (8), additions of any other tunnel safety provisions (e.g., $\vec{x}=(1,1,0), \vec{y}=(0,1,1,0)$, and $\vec{z}=(0,0,0,1))$ will definitely be within the safety targets. On the contrary, if the solution does not satisfy constraints (6) to (8), any combinations with deductions of any tunnel safety provisions (e.g., $\vec{x}=(1,0,0), \vec{y}=$ $(0,0,1,0)$, and $\vec{z}=(0,0,0,1))$ will also be unacceptable according to the safety target. Similar ideas of domination have been applied by other research in operational research (e.g., [12-17]) Two domination rules are illustrated as follows.

Rule 1. If a combination of candidate tunnel safety provisions does not satisfy constraints (6) to (8), all the other combinations with deductions of tunnel safety provisions will also not be acceptable according to the safety targets.
Rule 2. If a combination of candidate tunnel safety provisions fulfils constraints (6) to (8), all the other combinations with higher AW value (objective function (2)) are not the optimal solution.

By taking advantage of the special structure of the problem, we design a Bi-Section Search and Bound Algorithm (BSSBA) to solve the problem. The BSSBA is presented as follows.

Step 0. Calculate the AW values (objective function (2)) for all the possible combinations satisfying constraints (3) to (5).

Step 1. Rank the combinations in terms of AW values: $\mathrm{AW}^{(0)}, \mathrm{AW}^{(1)}, \ldots, \mathrm{AW}^{(N-1)}$, where $N$ is the number of available combinations.

Step 2. Check whether or not the combination with median AW value satisfies the constraints (6) to (8): if yes, remove all the combinations with higher AW values (due to domination rule number 2); otherwise, remove the combination itself and all the combinations with deductions of tunnel safety provisions (due to domination rule number 1).

Step 3. Rerank the remaining combinations in terms of AW values and go to Step 2.

Step 4. Stop when optimal solution is found.

\section{An Illustrative Numerical Study}

In this section, we use a numerical study to illustrate the model and algorithm. We assume that there are two types of tunnel ventilation systems: longitudinal ventilation system and transverse ventilation system; three types of fire detection system: line-type heat-sensing cable, smoke detectors, and the automatic incident detectors; and two types of fire verification system: Closed-Circuit Television (CCTV) and emergency telephones. The purchase costs, maintenance costs, and operating costs in this study are presented in Table 1 . The life spans of the safety provisions are assumed to be 30 years. The Minimum Attractive Rate of Return (MARR) is assumed to be $8 \%$. We use the 0.9 cut based societal risk and 0.9 percentile based individual risk and expected number of fatalities as the risk indices. The safety targets for societal risk, individual risk, and expected number of fatalities are $10^{-3} / N^{2}, 10^{-8}$, and 0.5 , respectively.

According to life cycle cost analysis (LCCA), the annual worth for various types of tunnel safety provisions can be estimated by

$$
\begin{aligned}
V^{i} & =V_{p}^{i} \times\left(\frac{A}{P}, 8 \%, 30\right)+V_{m}^{i}+V_{o}^{i}, \\
D^{i} & =D_{p}^{i} \times\left(\frac{A}{P}, 8 \%, 30\right)+D_{m}^{i}+D_{o}^{i}, \\
F^{i} & =F_{p}^{i} \times\left(\frac{A}{P}, 8 \%, 30\right)+F_{m}^{i}+F_{o}^{i} .
\end{aligned}
$$


TABLE 1: The purchase costs, maintenance costs, and operating costs for various types of tunnel safety provisions.

\begin{tabular}{|c|c|c|c|c|}
\hline Tunnel safety provisions & Types & $\begin{array}{c}\text { Purchase } \\
\text { costs (million } \\
\text { SD) }\end{array}$ & $\begin{array}{l}\text { Maintenance } \\
\text { costs (million } \\
\text { SD per year) }\end{array}$ & $\begin{array}{c}\text { Operating } \\
\text { costs (million } \\
\text { SD per year) }\end{array}$ \\
\hline \multirow{2}{*}{ Tunnel ventilation system } & Longitudinal & 50 & 5 & 0.8 \\
\hline & Transverse & 80 & 8 & 1.8 \\
\hline \multirow{3}{*}{ Fire detection system } & Heat & 4 & 0.4 & 0.1 \\
\hline & Smoke & 8 & 0.8 & 0.1 \\
\hline & AID & 4 & 0.4 & 0.1 \\
\hline \multirow{2}{*}{ Fire verification system } & CCTV & 25 & 2.5 & 0.4 \\
\hline & Emergency telephone & 20 & 2 & 0.1 \\
\hline
\end{tabular}

TABLE 2: The annual worth of the candidate tunnel safety provisions.

\begin{tabular}{lcc}
\hline Tunnel safety provisions & Types & $\begin{array}{c}\text { Annual } \\
\text { worth } \\
\text { (million SD) }\end{array}$ \\
\hline Tunnel ventilation system & Longitudinal & 10.24 \\
& Transverse & 16.904 \\
\hline \multirow{2}{*}{ Fire detection system } & Heat & 0.8552 \\
& Smoke & 1.6104 \\
Fire verification system & AID & 0.8552 \\
& CCTV & 5.12 \\
\hline
\end{tabular}

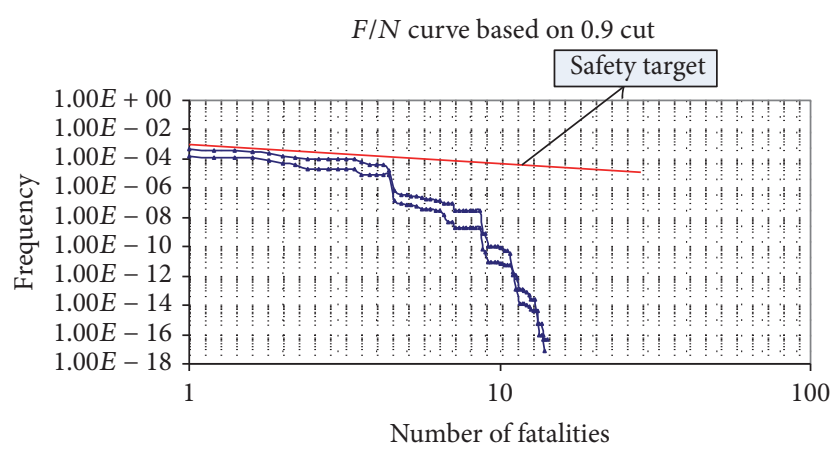

FIGURE 1: Societal risk of the optimal combination.

Table 2 illustrates the estimation results for annual worth of tunnel safety provisions.

The problem can be efficiently solved by the proposed BSSBA algorithm in 9 iterations (as detailed in Table 3).

As can be seen in Table 3, the optimal combination of tunnel safety provisions is 16.2152 million Singapore dollars. The longitudinal ventilation system, heat detector based fire detection system, and CCTV based fire verification system are chosen. The societal risk, individual risk, and expected number of fatalities of the combination are presented in Figures 1-3.

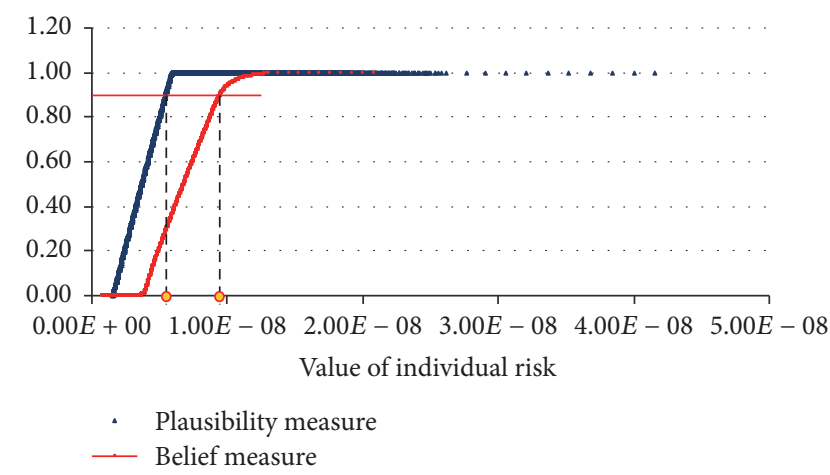

FIGURE 2: Individual risk of the optimal combination.

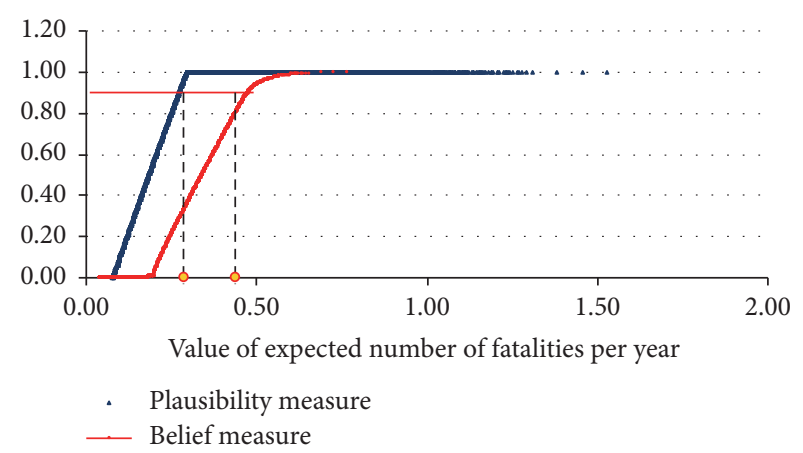

FIGURE 3: Expected number of fatalities per year of the optimal combination.

\section{Conclusions}

Tunnel safety provisions are the assets of urban road tunnels which are installed and implemented to reduce the tunnel risks, which are basically selected by expert judgment in practice. However, they are usually not optimal selection. In this study, an optimization model is proposed to obtain the optimal solution for the selection of tunnel safety provisions. The objective function is to minimize the life cycle costs of tunnel safety provisions, which is subject to the requirements for tunnel safety provisions and the safety targets. Finally, by taking advantage of the special structure of the optimization 
TABLE 3: Iterations for solving the problem.

\begin{tabular}{lcccccc}
\hline & Combinations & $\begin{array}{c}\text { Number of remainder } \\
\text { combinations }\end{array}$ & $\begin{array}{c}\text { Annual worth } \\
\text { (AW) (million SD) }\end{array}$ & \multicolumn{2}{c}{ Safety evaluation } \\
Societal risk & Individual risk & EV value \\
\hline Iteration 1 & $\vec{x}=(0,1), \vec{y}=(1,1,0), \vec{z}=(1,0)$ & 32 & 24.4896 & Safe & Safe & Safe \\
Iteration 2 & $\vec{x}=(1,0), \vec{y}=(1,0,0), \vec{z}=(1,1)$ & 16 & 20.0912 & Safe & Safe & Safe \\
Iteration 3 & $\vec{x}=(1,0), \vec{y}=(0,2,3), \vec{z}=(0,1)$ & 14 & 16.5816 & Risky & Safe & Safe \\
Iteration 4 & $\vec{x}=(1,0), \vec{y}=(1,1,0), \vec{z}=(1,0)$ & 7 & 16.9704 & Safe & Safe & Safe \\
Iteration 5 & $\vec{x}=(1,0), \vec{y}=(1,0,1), \vec{z}=(0,1)$ & 6 & 15.8264 & Risky & Safe & Safe \\
Iteration 6 & $\vec{x}=(1,0), \vec{y}=(0,1,0), \vec{z}=(0,1)$ & 5 & 15.7264 & Risky & Safe & Safe \\
Iteration 7 & $\vec{x}=(1,0), \vec{y}=(1,0,0), \vec{z}=(1,0)$ & 3 & 16.2152 & Safe & Safe & Safe \\
Iteration 8 & $\vec{x}=(1,0), \vec{y}=(0,0,1), \vec{z}=(0,1)$ & 2 & 14.9712 & Risky & Safe & Safe \\
Iteration 9 & $\vec{x}=(1,0), \vec{y}=(1,0,0), \vec{z}=(0,1)$ & 1 & 14.9712 & Risky & Safe & Safe \\
\hline
\end{tabular}

$*$ indicates the optimal solution.

model, a Bi-Section Search and Bound Algorithm (BSSBA) is designed to efficiently solve the problem.

\section{Competing Interests}

The authors declare that there is no conflict of interests regarding the publication of this paper.

\section{References}

[1] A. N. Beard, "Fire safety in tunnels," Fire Safety Journal, vol. 44, no. 2, pp. 276-278, 2009.

[2] A. Beard and C. Carvel, The Handbook of Tunnel Fire Safety, Thomas Telford, London, UK, 1st edition, 2005.

[3] T. F. Fwa and K. C. Sinha, "Pavement performance and life-cycle cost analysis," Journal of Transportation Engineering, vol. 117, no. 1, pp. 33-46, 1991.

[4] C. C. Mitropoulou, N. D. Lagaros, and M. Papadrakakis, "Advances in life cycle cost analysis of structures," in Computational Methods in Earthquake Engineering, vol. 21 of Computational Methods in Applied Sciences, pp. 539-557, Springer, Berlin, Germany, 2011.

[5] D. A. Arditi and H. M. Messiha, "Life-cycle costing in municipal construction projects," Journal of Infrastructure Systems, vol. 2, no. 1, pp. 5-14, 1996.

[6] Y. Asiedu and P. Gu, "Product life cycle cost analysis: state of the art review," International Journal of Production Research, vol. 36, no. 4, pp. 883-908, 1998.

[7] H. D. Sherali, J. Desai, and T. S. Glickman, "Optimal allocation of risk-reduction resources in event trees," Management Science, vol. 54, no. 7, pp. 1313-1321, 2008.

[8] Q. Meng, X. Qu, K. T. Yong, and Y. H. Wong, "QRA modelbased risk impact analysis of traffic flow in urban road tunnels," Risk Analysis, vol. 31, no. 12, pp. 1872-1882, 2011.

[9] Q. Meng, X. Qu, X. Wang, V. Yuanita, and S. C. Wong, "Quantitative risk assessment modeling for nonhomogeneous urban road tunnels," Risk Analysis, vol. 31, no. 3, pp. 382-403, 2011.

[10] X. Qu, Q. Meng, Y. H. Wong, and Y. Vivi, "Design and implementation of a quantitative risk assessment software tool for Singapore's road tunnels," Expert Systems with Applications, vol. 38, no. 11, pp. 13827-13834, 2011.
[11] Q. Meng and X. Qu, "Uncertainty propagation in quantitative risk assessment modeling for fire in road tunnels," IEEE Transactions on Systems, Man and Cybernetics Part C: Applications and Reviews, vol. 42, no. 6, pp. 1454-1464, 2012.

[12] Z. Liu, S. Wang, W. Chen, and Y. Zheng, "Willingness to board: a novel concept for modeling queuing up passengers," Transportation Research Part B: Methodological, vol. 90, pp. 7082, 2016.

[13] S. Wang, "Optimal sequence of container ships in a string," European Journal of Operational Research, vol. 246, no. 3, pp. 850-857, 2015.

[14] S. Wang, "Fundamental properties and pseudo-polynomialtime algorithm for network containership sailing speed optimization," European Journal of Operational Research, vol. 250, no. 1, pp. 46-55, 2016.

[15] L. Zhen, K. Wang, and H.-C. Liu, "Disaster relief facility network design in metropolises," IEEE Transactions on Systems, Man, and Cybernetics: Systems, vol. 45, no. 5, pp. 751-761, 2015.

[16] L. Zhen, T. Shen, S. Wang, and S. Yu, "Models on ship scheduling in transshipment hubs with considering bunker cost," International Journal of Production Economics, vol. 173, pp. 111-121, 2016.

[17] L. Zhen and K. Wang, "A stochastic programming model for multi-product oriented multi-channel component replenishment," Computers \& Operations Research, vol. 60, pp. 79-90, 2015. 

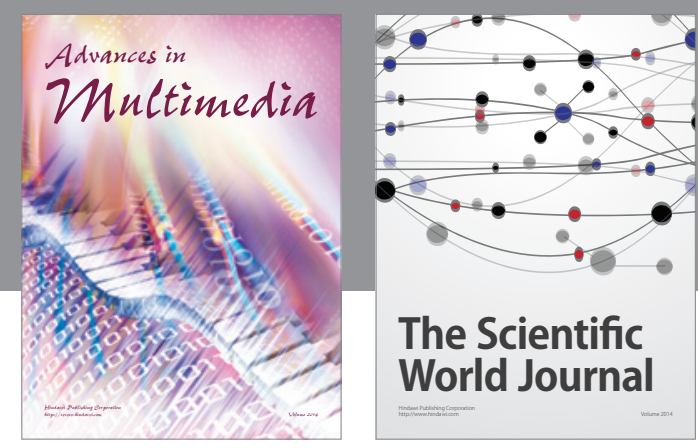

The Scientific World Journal
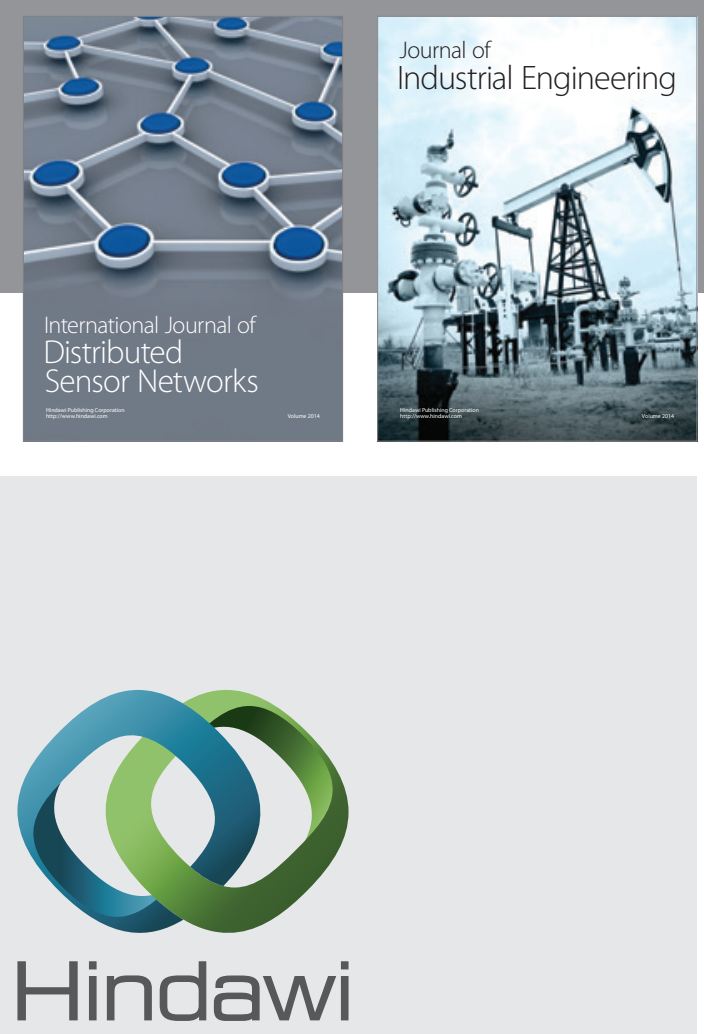

Submit your manuscripts at

http://www.hindawi.com

\section{Computer Networks} and Communications
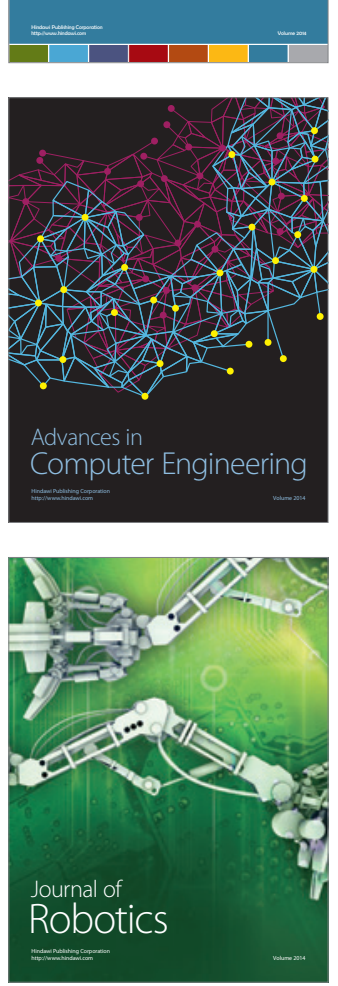
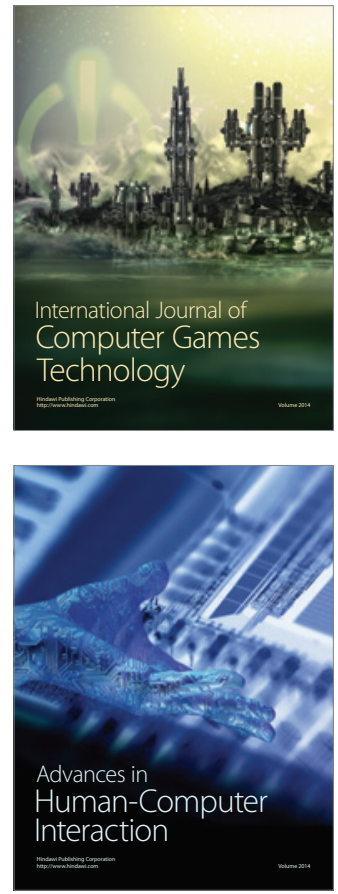
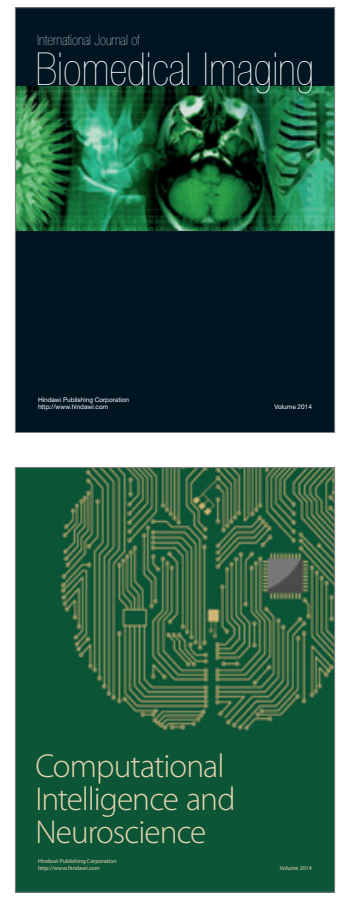
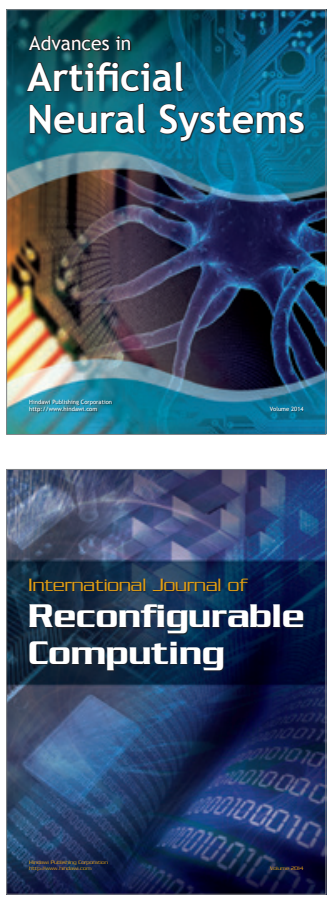
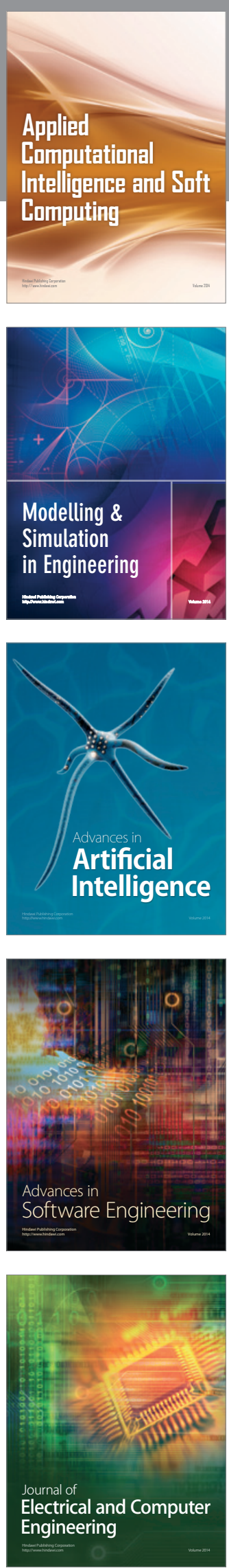